\title{
PENILAIAN KINERJA CUSTOMER RELATIONSHIP MANAGEMENT DALAM INDUSTRI PERBANKAN DENGAN MENGGUNAKAN METODE ANALYSIS HIERARCHY PROCESS (STUDI KASUS PADA BANK. XXX)
}

\author{
Mohammad Agung Saryatmo, Ahmad dan Inge Elsera Kristian \\ Program Studi Teknik Industri Universitas Tarumanagara Jakarta \\ e-mail: asaryatmo@gmail.com
}

\begin{abstract}
ABSTRAK
Bank XXX adalah perusahaan yang bergerak di industri jasa, memiliki delapan divisi membutuhkan karyawan yang dapat bekerja dengan baik agar kepuasan pelanggan dapat dicapai. Untuk itu, perlu adanya penilaian kinerja yang dilakukan pada Bank XXX. Hal ini bertujuan untuk mengetahui divisi mana yang bekerja secara maksimal dengan memberikan kriteria pembobotan yang sesuai dengan Bank XXX tersebut. Metode Analysis Hierarchy Process digunakan untuk memberikan pembobotan tersebut. AHP merupakan suatu model pendukung keputusan yang akan menguraikan masalah multi faktor atau multi kriteria yang kompleks menjadi suatu hirarki. Level pertama adalah tujuan, yang diikuti level faktor, kriteria, sub kriteria, dan seterusnya ke bawah hingga level terakhir dari alternatif. Penilaian akan dilakukan oleh top mangement dan divisi yang bersangkutan pada Bank XXX. Dasar teori yang digunakan untuk menyelesaikan permasalahan di Bank XXX adalah Customer Relationship Management. Dari hasil perhitungan dapat diketahui bahwa urutan prioritas Bank XXX yang mempunyai kriteria kinerja yang paling penting adalah Divisi Teknologi Informasi (0,198912), Divisi Logistik $(0,172157)$, Divisi Perbankan Internasional (0,124572), Divisi Audit Internal (0,119687), Divisi Perbankan Konsumer (0,107502), Divisi Pengembangan Operasi (0,099893), Divisi Sumber Daya Manusia (0,093967) dan Divisi Keuangan dan Akuntansi (0,083311). Kemudian dilakukan penilaian kinerja dengan Key Performance Indicator dan hasilnya adalah terdapat 1 KPI yang berwarna kuning. Hal ini berarti perlu dilakukannya suatu perbaikan agar kinerja perusahaan dapat berlangsung dengan baik.
\end{abstract}

Kata Kunci: Analysis Hierarchy Process, Customer Relationship Management, Kinerja Karyawan, Key Performance Indicator

\begin{abstract}
Bank XXX is company engaged in the service industry, has eight divisions need employees who can work well so that customer satisfaction can be achieved. Hence, the need for performance assessment conducted at Bank XXX. It aims to determine which division works optimally by providing the weighting criteria in accordance with the Bank XXX. Method of Analysis Hierarchy Process is used to provide the weighting. AHP is a decision support model which will outline the multi-factor problem or the complex multi-criteria into a hierarchy. The first level is the goal, which is followed by the level of factors, criteria, sub-criteria, and so on down to the last level of the alternatives. Assessment will be carried out by top mangement and the concerned division at Bank XXX. Basic theory used to solve the problems at Bank XXX is the Customer Relationship Management. From the results of calculations could be seen that the order of priority of Bank XXX that have the most important performance criterion is the Information Technology Division (0.198912), Logistics Division (0.172157), International Banking Division (0.124572), the Internal Audit Division (0, 119 687), Consumer Banking Division (0.107502), Operations Development Division (0.099893), Human Resources Division (0.093967) and the Finance and Accounting Division (0.083311). Then an assessment of performance by Key Performance Indicator and the result is that there is one KPI yellow. This means it needs to be an improvement for the performance of the company can take place properly.
\end{abstract}

Keywords: Analysis Hierarchy Process, Customer Relationship Management, Employee Performance, Key Performance Indicator

\section{PENDAHULUAN}

Pada era globalisasi saat ini, persaingan dalam dunia bisnis semakin bertambah ketat. Persaingan ini menuntut para pelaku bisnis untuk mampu memaksimalkan kinerja perusahaannya agar dapat bersaing di pasar.
Perusahaan harus berusaha keras untuk mempelajari dan memahami kebutuhan dan keinginan pelanggannya. Dengan memahami kebutuhan, keinginan dan permintaan pelanggan, maka akan memberikan masukan penting bagi perusahaan untuk merancang 
strategi pemasaran agar dapat menciptakan kepuasan bagi pelanggannya.

Perusahaan yang bergerak dalam bidang jasa ini selalu memprioritaskan kepuasan nasabah, untuk itu perlu adanya penilaian kinerja divisi-divisi yang ada yang dilakukan oleh para Top Management. Metode penilaian ini dilakukan dengan menggunakan metode Analysis Hierarchy Process (AHP). Tujuan dari penelitian ini adalah mengetahui pengaruh hubungan kerja Top Management dengan kinerja karyawan dan untuk mengetahui kinerja karyawan pada Bank XXX terhadap kepuasan nasabah.

\section{Kepuasan Pelanggan \\ TINJAUAN PUSTAKA}

Kepuasan pelanggan terhadap suatu produk merupakan faktor yang sangat penting dalam kegiatan pemasaran produk. Kepuasan dipengaruhi oleh beberapa faktor dan tidak dapat dihitung secara sistematis dengan tepat, karena perbedaan pandangan terhadap kepuasan. Manfaat suatu hubungan yang baik antara pelanggan dan perusahaan adalah pelayanan yang lebih baik antara pelanggan dan perusahaan adalah pelayanan yang lebih baik dan cepat serta perhatian yang lebih terhadap pelanggan. Dengan demikian akan tercipta sistem pelayanan yang sesuai dengan kebutuhan pelanggan [1].

\section{Customer Relationship Management (CRM)}

Fokus dari CRM pada penelitian ini adalah pelanggan yang dalam dunia perbankan berarti nasabah. Implementasi CRM di dunia perbankan meliputi fungsi-fungsi yang terintegrasi dari sistem pemasaran, penjualan serta pelayanan [2].

\section{Hubungan CRM dengan Loyalitas Pelanggan}

Loyalitas pelanggan adalah hasil yang didapat dari suatu organisasi yang menciptakan manfaat untuk para pelanggannya sehingga mereka akan melakukan tranksaksi dengan suatu perusahaan. Loyalitas pelanggan dapat diciptakan tetapi harus adanya kerja sama antara perusahaan dengan pelanggannya melalui pemberian manfaat antara kedua pihak [2].

\section{Klasifikasi CRM}

CRM dapat diklasifikasikan menjadi tiga level yang berbeda, yaitu Strategic CRM, Operational CRM, dan Analytical CRM. Dapat dijelaskan pada Tabel 1.

Tabel 1. Klasifikasi CRM [3]

\begin{tabular}{|c|c|}
\hline Level CRM & Karakteristik yang Mendominasi \\
\hline Strategic & $\begin{array}{l}\text { Sebuah pandangan yang bersifat top- } \\
\text { down yang memandang CRM sebagai } \\
\text { inti dan sebuah strategi bisnis yang } \\
\text { berorientasi kepada konsumen dan } \\
\text { mempunyai tujuan untuk memenangkan } \\
\text { dan menjaga konsumen yang dapat } \\
\text { memberikan keuntungan. }\end{array}$ \\
\hline Operational & $\begin{array}{l}\text { Sebuah pandangan terhadap CRM yang } \\
\text { fokusnya adalah otomasi terhadap } \\
\text { bidang penting seperti service, } \\
\text { marketing, dan lain-lain. }\end{array}$ \\
\hline Analytical & $\begin{array}{l}\text { Sebuah pandangan yang bersifat } \\
\text { bottom-up terhadap CRM yang } \\
\text { berfokuskan pada data konsumen yang } \\
\text { kemudian akan digunakan untuk } \\
\text { kepentingan pembentukan strategi. }\end{array}$ \\
\hline
\end{tabular}

\section{Konsep Pengukuran Kinerja}

Kinerja pada umumnya menunjuk pada keluaran dan hasil yang diperoleh dari proses, produk dan layanan dimana terdapat evaluasi dan perbandingan relatif terhadap tujuan, standar, dan organisasi lain. Sedangkan pengukuran merupakan jenis dari informasi numerik yang mengukur masukan, keluaran dan dimensi kinerja dari proses, produk, layanan, dan hasil organisasi secara keseluruhan [4].

\section{Manfaat Kinerja Perusahaan}

Penilaian kinerja mempunyai beberapa manfaat dan tujuan bagi organisasi dan karyawan atau divisi yang dinilai, yaitu [4]:

a. Performance Improvement, yaitu memungkinkan pegawai dan manajer untuk mengambil tindakan yang berhubungan dengan peningkatan kinerja.

b. Compensation Adjustment, yaitu membantu para pengambil keputusan untuk menentukan siapa saja yang berhak menerima kenaikan gaji atau sebaliknya. 
Penilaian Kinerja Customer Relationship Management dalam Industri Perbankan dengan Menggunakan Metode Analysis Hierarchy Process (Studi Kasus Pada Bank. XXX)

Mohammad Agung Saryatmo, Ahmad dan Inge Elsera Kristian

c. Placement Decision, yaitu menentukan promosi, transfer, dan demotion.

d. Training and Development, yaitu mengevaluasi kebutuhan pelatihan dan pengembangan bagi pegawai agar kinerja mereka lebih optimal.

e. Career Planning and Development, yaitu memandu untuk menentukan jenis karir dan potensi karir yang dicapai.

f. Staffing Process Deficiencies, yaitu mempengaruhi prosedur perekrutan pegawai.

g. Informational Inaccuracies and Job-design Erros, yaitu membantu menjelaskan apa saja kesalahan yang telah terjadi dalam manajemen sumber daya manusia terutama di bidang informasi job-analysis, job desgin, dan sistem informasi manajemen sumber daya manusia.

h. Equal Employment Opportunity, yaitu menunjukkan bahwa placement decision tidak diskriminatif.

i. External Challenges, yaitu kinerja karyawan dipengaruhi oleh faktor eksternal seperti keluarga, keuangan pribadi, kesehatan, dan lain-lainnya.

\section{Analysis Hierarchy Process}

AHP merupakan suatu model pendukung keputusan yang dikembangkan oleh Thomas L. Saaty. Hirarki didefinisikan sebagai suatu representasi dari sebuah permasalahan yang kompleks dalam suatu struktur multi level dimana level pertama adalah tujuan, yang diikuti level faktor, kriteria, sub kriteria, dan seterusnya ke bawah hingga level terakhir dari alternatif. Dengan hirarki, suatu masalah yang kompleks dapat diuraikan ke dalam kelompokkelompoknya yang kemudian diatur menjadi suatu bentuk hirarki sehingga permasalahan akan tampak lebih terstruktur dan sistematis [4].

\section{Skala Persepsi}

AHP mempunyai input dasar dalam bentuk skala ratio. Dalam model AHP digunakan batas 1 sampai 9 yang dianggap cukup mewakili persepsi manusia, seperti pada Tabel 2.

Tabel 2. Skala Persepsi [5]

\begin{tabular}{|c|c|c|}
\hline $\begin{array}{c}\text { Tingkat } \\
\text { Ke- } \\
\text { pentingan }\end{array}$ & Definisi & Keterangan \\
\hline 1 & $\begin{array}{c}\text { Sama } \\
\text { Kepentingan } \\
\text { nya } \\
\end{array}$ & $\begin{array}{l}\text { Kedua elemen mempunyai } \\
\text { pengaruh yang sama }\end{array}$ \\
\hline 3 & $\begin{array}{l}\text { Sedikit } \\
\text { Lebih } \\
\text { Penting }\end{array}$ & $\begin{array}{l}\text { Pengalaman dan penilaian } \\
\text { sangat memihak satu } \\
\text { elemen dibandingkan } \\
\text { dengan elemen } \\
\text { pasangannya }\end{array}$ \\
\hline 5 & $\begin{array}{l}\text { Lebih } \\
\text { Penting }\end{array}$ & $\begin{array}{l}\text { Satu elemen sangat disukai } \\
\text { dan secara praktis } \\
\text { dominasinya sangat nyata, } \\
\text { dibandingkan dengan } \\
\text { elemen pasangannya }\end{array}$ \\
\hline 7 & $\begin{array}{l}\text { Sangat } \\
\text { Penting }\end{array}$ & $\begin{array}{l}\text { Satu elemen terbukti } \\
\text { sangat disukai }\end{array}$ \\
\hline 9 & $\begin{array}{l}\text { Mutlak lebih } \\
\text { penting }\end{array}$ & $\begin{array}{l}\text { Satu elemen terbukti } \\
\text { mutlak lebih disukai } \\
\text { dibandingkan dengan } \\
\text { pasangannya, pada } \\
\text { keyakinan tertinggi }\end{array}$ \\
\hline $2,4,6,8$ & Nilai Tengah & $\begin{array}{l}\text { Diberikan bila terdapat } \\
\text { keraguan penilaian } \\
\text { diantara dua tingkat } \\
\text { kepentingan yang } \\
\text { berdekatan. }\end{array}$ \\
\hline
\end{tabular}

\section{METODE PENELITIAN}

Metodologi penelitian dapat dilihat pada Gambar 1.

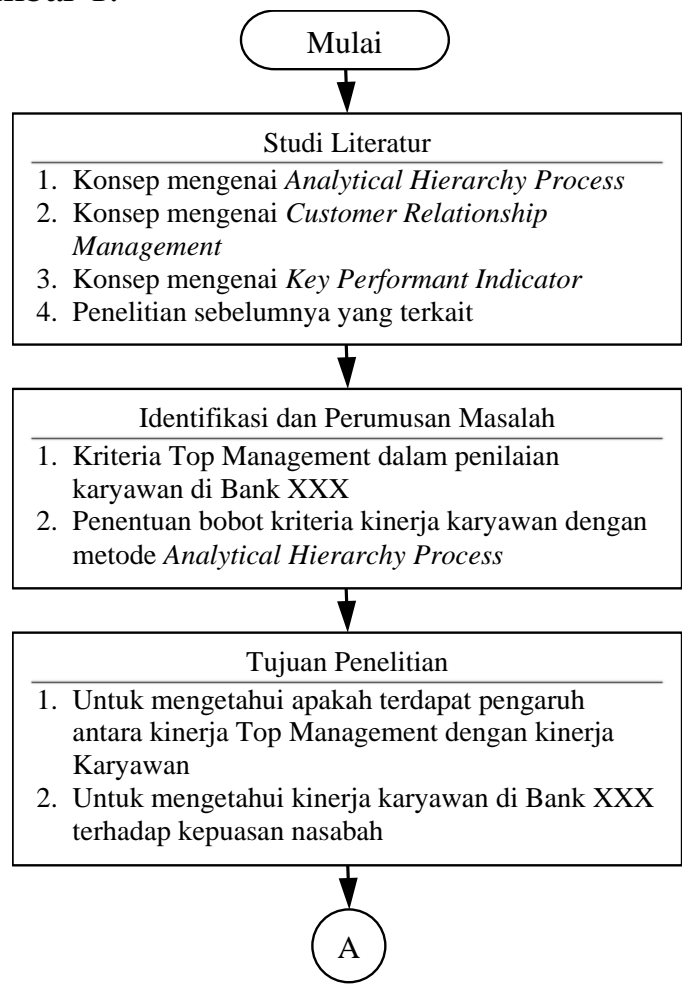

Gambar 1. Metode Penelitian 


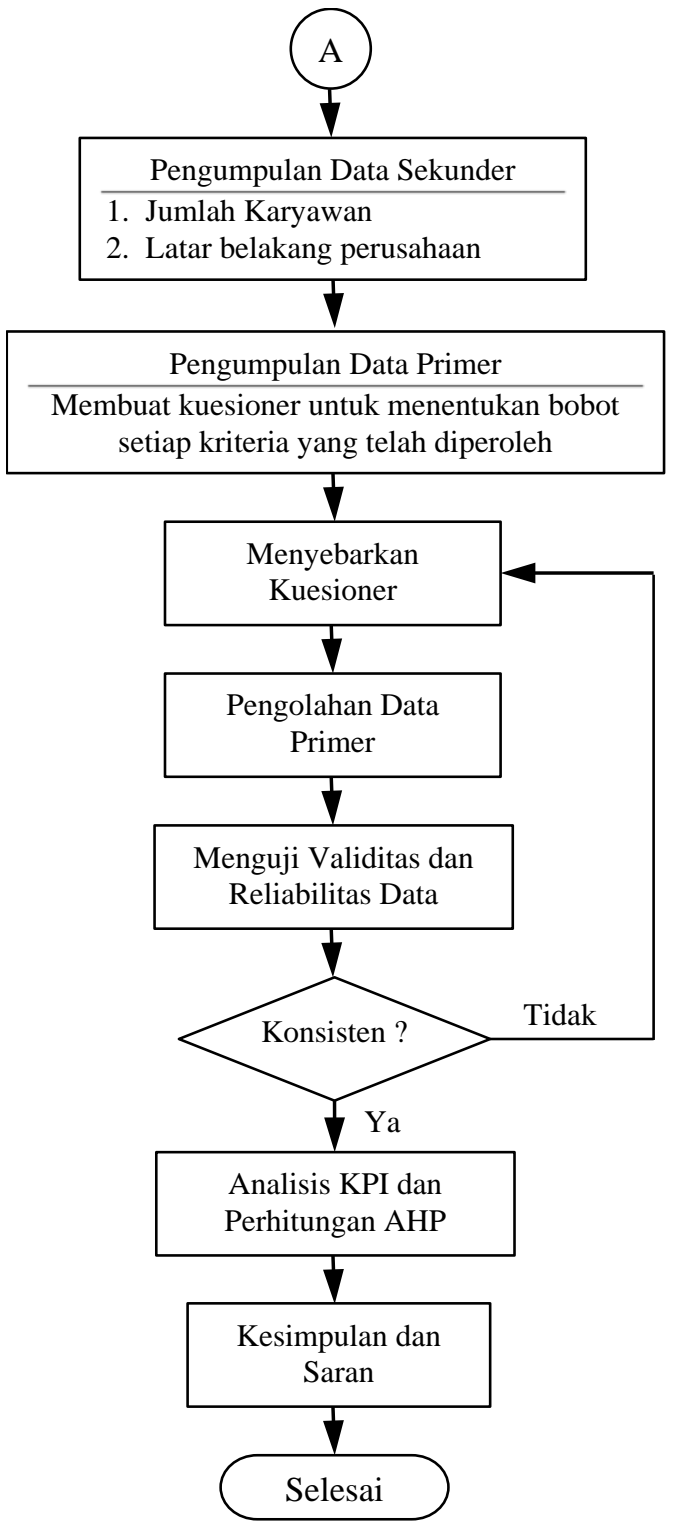

Lanjutan Gambar 1. Metode Penelitian

\section{HASIL DAN PEMBAHASAN}

Hasil analisis preferensi gabungan dari 86 responden menunjukkan bahwa kriteria ketrampilan teknis 2 kali lebih penting dari penampilan atau kepribadian, 5 kali lebih penting dari kriteria kemampuan mengurus tugas dan 3 kali lebih penting dari hubungan kerja. Sedangkan kriteria penampilan atau kepribadian 2 kali lebih penting dari kriteria kemampuan mengurus tugas dan 5 kali lebih penting dari kriteria hubungan kerja. Tetapi kriteria kemampuan mengurus tugas 2 kali lebih penting dibandingkan dengan kriteria hubungan kerja. Sehingga matriks perbandingan hasil preferensi di atas adalah:
Tabel 3. Nilai Random Indeks ( $R I)$

\begin{tabular}{cccccccc}
\hline $\mathrm{N}$ & 1 & 2 & 3 & 4 & 5 & 6 & 7 \\
\hline $\mathrm{RI}$ & 0 & 0 & 0,58 & 0,9 & 1,12 & 1,24 & 1,32 \\
\hline \hline $\mathrm{N}$ & 8 & 9 & 10 & 11 & 12 & 13 & 14 \\
\hline $\mathrm{RI}$ & 1,41 & 1,45 & 1,49 & 1,51 & 1,48 & 1,56 & 1,57 \\
\hline
\end{tabular}

Tabel 4. Matriks Pembobotan Hirarki untuk Semua Kriteria

\begin{tabular}{ccccc} 
& KT & P & KMT & HK \\
\hline KT & 1 & 2 & 5 & 3 \\
$\mathrm{P}$ & $1 / 2$ & 1 & 2 & 5 \\
$\mathrm{KMT}$ & $1 / 5$ & $1 / 2$ & 1 & 2 \\
$\mathrm{HK}$ & $1 / 3$ & $1 / 5$ & $1 / 2$ & 1 \\
\hline
\end{tabular}

Tabel 5. Matriks Faktor Pembobotan Hirarki untuk Semua Kriteria yang Disederhanakan

\begin{tabular}{lcccc}
\cline { 2 - 5 } & KT & P & KMT & HK \\
\hline KT & 1 & 2 & 5 & 3 \\
P & 0,5 & 1 & 2 & 5 \\
KMT & 0,2 & 0,5 & 1 & 2 \\
HK & 0,333333 & 0,2 & 0,5 & 1 \\
\hline Jumlah & 2,033333 & 3,7 & 8,5 & 11 \\
\hline
\end{tabular}

Tabel 6. Matriks Faktor Pembobotan Hirarki untuk Semua Kriteria yang Dinormalkan

\begin{tabular}{ccccc}
\cline { 2 - 5 } & KT & P & KMT & HK \\
\hline KT & 0,491803 & 0,245902 & 0,098361 & 0,163934 \\
P & 0,540541 & 0,27027 & 0,135135 & 0,054054 \\
KMT & 0,588235 & 0,235294 & 0,117647 & 0,058824 \\
HK & 0,272727 & 0,454545 & 0,181818 & 0,090909 \\
Jumlah & 1,893306 & 1,206011 & 0,532961 & 0,367721 \\
$\begin{array}{c}\text { Baris } \\
\text { Eigen }\end{array}$ & 0,473327 & 0,301503 & 0,13324 & 0,09193 \\
Vektor & 0 & & & \\
\hline
\end{tabular}

Dari perhitungan di atas, dapat diketahui:

$\kappa_{\text {maks }}$ sebesar 4,221767, Consistency Index sebesar 0,073922 dan Consistency Random sebesar 0,082136. Karena CR $<0,100$ berarti preferensi responden adalah konsisten. Dapat disimpulkan bahwa kriteria kemampuan teknis merupakan kriteria yang paling tinggi di Bank $\mathrm{X}$ dengan bobot 0,473327 atau 47,33\%, kemudian kriteria penampilan atau kepribadian dengan bobot 0,301503 atau 30,15\%, kriteria kemampuan mengurus tugas dengan bobot 0,13324 atau $13,33 \%$, dan yang terakhir adalah kriteria hubungan kerja dengan bobot 0,09193 atau $9,2 \%$. 
Penilaian Kinerja Customer Relationship Management dalam Industri Perbankan dengan Menggunakan Metode Analysis Hierarchy Process (Studi Kasus Pada Bank. XXX)

Mohammad Agung Saryatmo, Ahmad dan Inge Elsera Kristian

Tabel 7. Vektor Prioritas

\begin{tabular}{lcccc} 
& KT & P & KMT & HK \\
\hline KT & 1 & 2 & 3 & 2 \\
P & 0,5 & 1 & 2 & 3 \\
KMT & 0,333333 & 0,5 & 1 & 2 \\
HK & 0,5 & 0,333333 & 0,5 & 1 \\
\hline
\end{tabular}

Dengan demikian dapat diperoleh vektor prioritasnya, yaitu:

$$
\begin{array}{ll}
\sqrt[4]{1 \times 2 \times 3 \times 3} & =1,86 \\
\sqrt[4]{0.5 \times 1 \times 2 \times 3} & =1,31 \\
\sqrt[4]{0.333 \times 0.5 \times 1 \times 2} & =0,75 \\
\sqrt[4]{0.5 \times 0.333 \times 0.5 \times 1} & =0,53 \\
\text { Total } & =4,45
\end{array}
$$

Vektor prioritas: $\quad 1,86: 4,45=0,417978$

$$
\begin{aligned}
& 1,31: 4,45=0,294382 \\
& 0,75: 4,45=0,168539 \\
& 0,53: 4,45=0,119101
\end{aligned}
$$

\section{Perhitungan Faktor Evaluasi untuk Kriteria Ketrampilan Teknis}

Perbandingan berpasangan untuk kriteria ketrampilan teknis pada 10 divisi yaitu perbandingan berpasangan antara Divisi Audit Internal (1) terhadap Divisi Keuangan dan Akuntansi (2), Divisi Teknologi Informasi (3), Divisi Pengembangan Operasi (4), Divisi Perbankan Konsumer (5), Divisi Perbankan
Internasional (6), Divisi Sumber Daya Manusia (7), dan Divisi Logistik (8), dan sebaliknya. Kemudian, dibuatlah matriksnya seperti pada Tabel 8 dan 9.

Perhitungan ini didapatkan dari tiap kolom dibagi dengan jumlah total pada kolom yang bersangkutan. Maka, akan diperoleh bobot relatif yang dinormalkan. Nilai vektor eigen dihasilkan dari rata-rata nilai bobot relatif untuk tiap baris. Kemudian akan didapatkan nilai $K_{\text {maks }}$ atau nilai eigen maksimum dengan menjumlahkan hasil perkalian jumlah kolom dengan vektor eigen dan didapat hasil sebesar 8,949978. Karena matriks berordo 8 maka nilai indeks konsistensi (CI) adalah 1,410 (Tabel skala Saaty), dan nilai CR (CI/RI) adalah 0,096249. Karena CR $<0,100$ berarti preferensi responden adalah konsisten.

\section{Perhitungan Faktor Evaluasi untuk Kriteria Penampilan/Kepribadian}

Perhitungan dilanjutkan dengan kriteria penampilan atau kepribadian, kriteria kemampuan mengurus tugas, dan kriteria hubungan kerja pada Bank XXX. Dapat dilihat pada Tabel 9, Tabel 10 dan Tabel 11.

Tabel 8. Perhitungan Faktor Evaluasi Kriteria Ketrampilan Teknis

\begin{tabular}{ccccccccc}
\hline DIVISI & 1 & 2 & 3 & 4 & 5 & 6 & 7 & 8 \\
\hline 1 & 1 & 3 & $1 / 4$ & 3 & 5 & 1 & $1 / 2$ & $1 / 3$ \\
2 & $1 / 3$ & 1 & $1 / 7$ & $1 / 2$ & $1 / 4$ & 2 & 2 & $1 / 5$ \\
3 & 4 & 7 & 1 & 2 & 5 & 5 & 7 & 3 \\
4 & $1 / 3$ & 2 & $1 / 2$ & 1 & 2 & 3 & 3 & $1 / 2$ \\
5 & $1 / 5$ & 4 & $1 / 5$ & $1 / 2$ & 1 & $1 / 7$ & $1 / 3$ & $1 / 5$ \\
6 & 1 & $1 / 2$ & $1 / 5$ & $1 / 3$ & 7 & 1 & 2 & $1 / 2$ \\
7 & 2 & $1 / 2$ & $1 / 7$ & $1 / 3$ & 3 & $1 / 2$ & 1 & $1 / 2$ \\
8 & 3 & 5 & $1 / 3$ & 2 & 5 & 2 & 2 & 1 \\
\hline
\end{tabular}

Tabel 9. Perhitungan Matriks Faktor Evaluasi Kriteria Ketrampilan Teknis yang Disederhanakan

\begin{tabular}{ccccccccccc}
\hline Divisi & 1 & 2 & 3 & 4 & 5 & 6 & 7 & 8 & Jumlah $\begin{array}{c}\text { Eigen Vektor } \\
\text { yang di } \\
\text { Normalkan }\end{array}$ \\
\hline 1 & 0,0843 & 0,1304 & 0,0903 & 0,3103 & 0,1780 & 0,0683 & 0,0280 & 0,0535 & 0,9421 & 0,1178 \\
2 & 0,0281 & 0,0435 & 0,0516 & 0,0517 & 0,0089 & 0,1366 & 0,1122 & 0,0321 & 0,4645 & 0,0581 \\
3 & 0,3371 & 0,3043 & 0,3611 & 0,2069 & 0,1770 & 0,3415 & 0,3925 & 0,4813 & 2,6017 & 0,3251 \\
4 & 0,0281 & 0,0870 & 0,1806 & 0,1034 & 0,0708 & 0,2049 & 0,1682 & 0,0802 & 0,9232 & 0,1154 \\
5 & 0,0169 & 0,1740 & 0,0722 & 0,0517 & 0,0354 & 0,0098 & 0,0187 & 0,0321 & 0,4106 & 0,0513 \\
6 & 0,0843 & 0,0217 & 0,0516 & 0,0345 & 0,2378 & 0,0683 & 0,1122 & 0,0802 & 0,7212 & 0,0901 \\
7 & 0,1682 & 0,0217 & 0,0516 & 0,0345 & 0,1062 & 0,0341 & 0,0561 & 0,0802 & 0,5530 & 0,0691 \\
8 & 0,2528 & 0,2174 & 0,1204 & 0,2069 & 0,1770 & 0,1366 & 0,1122 & 0,1604 & 1,3836 & 0,1730 \\
\hline
\end{tabular}


Tabel 10. Perhitungan Faktor Evaluasi Kriteria Penampilan/Kepribadian

\begin{tabular}{ccccccccc}
\hline DIVISI & 1 & 2 & 3 & 4 & 5 & 6 & 7 & 8 \\
\hline 1 & 1 & $1 / 4$ & $1 / 2$ & 3 & $1 / 5$ & $1 / 3$ & $1 / 7$ & 3 \\
2 & 4 & 1 & 3 & 2 & $1 / 2$ & $1 / 3$ & $1 / 3$ & $1 / 5$ \\
3 & 2 & $1 / 3$ & 1 & $1 / 3$ & 2 & 3 & $1 / 5$ & $1 / 7$ \\
4 & $1 / 3$ & $1 / 2$ & 3 & 1 & $1 / 2$ & $1 / 2$ & 3 & $1 / 7$ \\
5 & 5 & 2 & $1 / 2$ & 2 & 1 & $1 / 3$ & 5 & 2 \\
6 & 3 & 3 & $1 / 3$ & 2 & 3 & 1 & 2 & 3 \\
7 & 7 & 3 & 5 & $1 / 3$ & $1 / 5$ & $1 / 2$ & 1 & $1 / 5$ \\
8 & $1 / 3$ & 5 & 7 & 7 & $1 / 2$ & $1 / 3$ & 5 & 1 \\
\hline
\end{tabular}

Tabel 11. Perhitungan Faktor Evaluasi Kriteria Penampilan/Kepribadian yang Disederhanakan

\begin{tabular}{ccccccccccc}
\hline Divisi & 1 & 2 & 3 & 4 & 5 & 6 & 7 & 8 & Jumlah & $\begin{array}{c}\text { Eigen Vektor } \\
\text { yang di } \\
\text { Normalkan }\end{array}$ \\
\hline 1 & 0,0441 & 0,0166 & 0,0246 & 0,1698 & 0,0253 & 0,0526 & 0,0086 & 0,3097 & 0,6513 & 0,0814 \\
2 & 0,1765 & 0,0663 & 0,1475 & 0,1132 & 0,0632 & 0,0526 & 0,0200 & 0,0206 & 0,6601 & 0,0825 \\
3 & 0,0882 & 0,0221 & 0,0492 & 0,0189 & 0,2532 & 0,4737 & 0,0120 & 0,0147 & 0,9320 & 0,1165 \\
4 & 0,0147 & 0,0331 & 0,1475 & 0,0566 & 0,0633 & 0,0790 & 0,1799 & 0,0147 & 0,5889 & 0,0736 \\
5 & 0,2206 & 0,1326 & 0,0246 & 0,1132 & 0,1266 & 0,0526 & 0,2999 & 0,2065 & 1,1765 & 0,1471 \\
6 & 0,1324 & 0,1989 & 0,0164 & 0,1132 & 0,3797 & 0,1579 & 0,1199 & 0,3097 & 1,4282 & 0,1785 \\
7 & 0,3088 & 0,1989 & 0,2459 & 0,0189 & 0,0353 & 0,0789 & 0,0560 & 0,0206 & 0,9574 & 0,1197 \\
8 & 0,0147 & 0,3315 & 0,3443 & 0,3962 & 0,0633 & 0,0526 & 0,2998 & 0,1032 & 1,6057 & 0,2007 \\
\hline
\end{tabular}

Akan didapatkan nilai $K_{\text {maks }}$ atau nilai eigen maksimum dengan menjumlahkan hasil perkalian jumlah kolom dengan vektor eigen dan didapat hasil sebesar 8,891323. Karena matriks berordo 8 maka nilai indeks konsistensi (CI) yang digunakan adalah 1,410 (tabel skala Saaty), sehingga didapatkan hasil sebesar 0,127332. Dan nilai CR (CI/RI) adalah
0,090306. Karena CR < 0,100 berarti preferensi responden adalah konsisten.

\section{Perhitungan Faktor Evaluasi untuk Kriteria Kemampuan Mengurus Tugas}

Perhitungan matriks faktor kriteria kemampuan mengurus tugas dapat dilihat pada tabel berikut:

Tabel 12. Perhitungan Faktor Evaluasi Kriteria Kemampuan Mengurus Tugas

\begin{tabular}{ccccccccc}
\hline DIVISI & 1 & 2 & 3 & 4 & 5 & 6 & 7 & 8 \\
\hline 1 & 1 & 3 & 5 & 3 & 7 & 2 & 5 & 3 \\
2 & $1 / 3$ & 1 & 3 & 2 & 5 & 3 & $1 / 5$ & $1 / 7$ \\
3 & $1 / 5$ & $1 / 3$ & 1 & $1 / 2$ & 3 & $1 / 2$ & 5 & 7 \\
4 & $1 / 3$ & $1 / 2$ & 2 & 1 & 3 & 3 & 2 & $1 / 5$ \\
5 & $1 / 7$ & $1 / 5$ & $1 / 3$ & $1 / 3$ & 1 & $1 / 5$ & 3 & 5 \\
6 & $1 / 2$ & $1 / 3$ & 2 & $1 / 3$ & 5 & 1 & $1 / 3$ & 5 \\
7 & $1 / 5$ & 5 & $1 / 5$ & $1 / 2$ & $1 / 3$ & 3 & 1 & $1 / 3$ \\
8 & $1 / 3$ & 7 & $1 / 7$ & 5 & $1 / 5$ & $1 / 5$ & 3 & 1 \\
\hline
\end{tabular}

Tabel 13. Perhitungan Faktor Evaluasi Kriteria Kemampuan Mengurus Tugas yang Disederhanakan

\begin{tabular}{ccccccccccc}
\hline Divisi & 1 & 2 & 3 & 4 & 5 & 6 & 7 & 8 & Jumlah & $\begin{array}{c}\text { Eigen Vektor } \\
\text { yang di } \\
\text { Normalkan }\end{array}$ \\
\hline 1 & 0,1266 & 0,1727 & 0,3606 & 0,2338 & 0,0113 & 0,1681 & 0,2560 & 0,1697 & 1,4987 & 0,1873 \\
2 & 0,0422 & 0,0576 & 0,2163 & 0,1558 & 0,2820 & 0,2521 & 0,0102 & 0,0081 & 1,0243 & 0,1280 \\
3 & 0,0253 & 0,0192 & 0,0721 & 0,0390 & 0,1692 & 0,0420 & 0,2560 & 0,1697 & 0,7925 & 0,0991 \\
4 & 0,0422 & 0,0288 & 0,1442 & 0,0779 & 0,1692 & 0,1681 & 0,1024 & 0,0113 & 0,7441 & 0,0930 \\
5 & 0,6329 & 0,0115 & 0,0240 & 0,0260 & 0,0564 & 0,0168 & 0,1536 & 0,2829 & 1,2041 & 0,1505 \\
6 & 0,0633 & 0,0192 & 0,1442 & 0,0390 & 0,2820 & 0,0840 & 0,0171 & 0,2829 & 0,9316 & 0,1164 \\
7 & 0,0253 & 0,2879 & 0,0144 & 0,0390 & 0,0819 & 0,2521 & 0,0512 & 0,0189 & 0,7076 & 0,0884 \\
8 & 0,0422 & 0,4030 & 0,0240 & 0,3896 & 0,0113 & 0,0168 & 0,1536 & 0,0566 & 1,0972 & 0,1371 \\
\hline
\end{tabular}


Penilaian Kinerja Customer Relationship Management dalam Industri Perbankan dengan Menggunakan Metode Analysis Hierarchy Process (Studi Kasus Pada Bank. XXX)

Mohammad Agung Saryatmo, Ahmad dan Inge Elsera Kristian

Akan didapatkan nilai $\kappa_{\text {maks }}$ atau nilai eigen maksimum dengan menjumlahkan hasil perkalian jumlah kolom dengan vektor eigen dan didapat hasil sebesar 8,87752, Karena matriks berordo 8 maka nilai indeks konsistensi (CI) yang digunakan adalah 1,410 (tabel skala Saaty), sehingga nilai CI yang didapatkan adalah 0,12536, Dan nilai CR (CI/RI) adalah 0,088908, Karena CR $<0,100$ berarti preferensi responden adalah konsisten,

\section{Perhitungan Faktor Evaluasi untuk Kriteria Hubungan Kerja}

Perhitungan matriks faktor kriteria kemampuan mengurus tugas dapat dilihat pada Tabel 14.
Akan didapatkan nilai $K_{\text {maks }}$ atau nilai eigen maksimum dengan menjumlahkan hasil perkalian jumlah kolom dengan vektor eigen dan didapat hasil sebesar 8,948294, Karena matriks berordo 8 maka nilai indeks konsistensi (CI) yang digunakan adalah 1,410 (tabel skala Saaty), sehingga nilai CI yang didapatkan sebesar 0,135471, Dan nilai CR (CI/RI) adalah 0,096078, Karena CR $<0,100$ berarti preferensi responden adalah konsisten.

\section{Total Ranking}

Setelah semua matriks berpasangan dihitung, maka dibuatlah tabel matriks hubungan antara kriteria dengan alternatif seperti ditunjukkan pada Tabel 16.

Tabel 14. Perhitungan Faktor Evaluasi Kriteria Hubungan Kerja

\begin{tabular}{ccccccccc}
\hline DIVISI & 1 & 2 & 3 & 4 & 5 & 6 & 7 & 8 \\
\hline 1 & 1 & $1 / 5$ & $1 / 3$ & 7 & $1 / 7$ & 3 & 5 & 3 \\
2 & 5 & 1 & 2 & $1 / 5$ & 5 & $1 / 3$ & $1 / 3$ & 4 \\
3 & 3 & $1 / 2$ & 1 & 3 & $1 / 3$ & $1 / 5$ & 5 & $1 / 7$ \\
4 & $1 / 7$ & 5 & $1 / 3$ & 1 & 5 & 3 & 2 & 2 \\
5 & 7 & $1 / 5$ & 3 & $1 / 5$ & 1 & 5 & $1 / 7$ & $1 / 3$ \\
6 & $1 / 3$ & 3 & 5 & $1 / 3$ & $1 / 5$ & 1 & 7 & $1 / 5$ \\
7 & $1 / 5$ & 3 & $1 / 5$ & $1 / 2$ & 7 & $1 / 7$ & 1 & $1 / 3$ \\
8 & $1 / 3$ & $1 / 4$ & 7 & $1 / 2$ & 3 & 5 & 3 & 1 \\
\hline
\end{tabular}

Tabel 15. Perhitungan Faktor Evaluasi Kriteria Hubungan Kerja yang Disederhanakan

\begin{tabular}{|c|c|c|c|c|c|c|c|c|c|c|}
\hline Divisi & 1 & 2 & 3 & 4 & 5 & 6 & 7 & 8 & Jumlah & $\begin{array}{c}\text { Eigen Vektor } \\
\text { yang di } \\
\text { Normalkan }\end{array}$ \\
\hline 1 & 0,0459 & 0,0246 & 0,0107 & 0,3992 & 0,0085 & 0,1697 & 0,0107 & 0,3330 & 1,0023 & 0,1252 \\
\hline 2 & 0,1376 & 0,0739 & 0,1068 & 0,0114 & 0,2963 & 0,0188 & 0,0178 & 0,2220 & 0,8846 & 0,1106 \\
\hline 3 & 0,2293 & 0,0369 & 0,0534 & 0,0171 & 0,0198 & 0,0113 & 0,2677 & 0,0159 & 0,8053 & 0,1007 \\
\hline 4 & 0,0066 & 0,0695 & 0,0178 & 0,0570 & 0,0119 & 0,1697 & 0,1071 & 0,2220 & 0,9615 & 0,1202 \\
\hline 5 & 0,3210 & 0,0148 & 0,1601 & 0,2851 & 0,0593 & 002829 & 0,0076 & 0,3700 & 1,1678 & 0,1460 \\
\hline 6 & 0,0153 & 0,2217 & 0,2669 & 0,0190 & 0,0119 & 0,0566 & 0,3748 & 0,0222 & 0,9883 & 0,1235 \\
\hline 7 & 0,2293 & 0,2217 & 0,0107 & 0,0285 & 0,4148 & 0,0081 & 0,0535 & 0,0370 & 1,0035 & 0,1254 \\
\hline 8 & 0,0153 & 0,0369 & 0,0285 & 0,0285 & 0,1778 & 0,2829 & 0,1606 & 0,1110 & 1,1867 & 0,1483 \\
\hline
\end{tabular}

Tabel 16. Matriks Hubungan antara Kriteria dengan Alternatif

\begin{tabular}{ccccc}
\hline $\begin{array}{c}\text { Kriteria } \\
\text { Divisi }\end{array}$ & KT & P & KMT & HK \\
\hline 1 & 0,1178 & 0,0814 & 0,1873 & 0,1253 \\
2 & 0,0581 & 0,0825 & 0,1280 & 0,1106 \\
3 & 0,3252 & 0,1165 & 0,0991 & 0,1007 \\
4 & 0,1154 & 0,0736 & 0,0930 & 0,1202 \\
5 & 0,0513 & 0,1471 & 0,1505 & 0,1460 \\
6 & 0,0902 & 0,1785 & 0,1165 & 0,1235 \\
7 & 0,0691 & 0,1197 & 0,0884 & 0,1254 \\
8 & 0,1730 & 0,2007 & 0,1371 & 0,1483 \\
\hline
\end{tabular}


Untuk mencari total rangking untuk masing-masing divisi adalah dengan cara mengalikan faktor evaluasi masing-masing alternatif dengan faktor bobot.

$$
\left(\begin{array}{llll}
0,11777 & 0,081418 & 0,187339 & 0,125284 \\
0,05807 & 0,08251 & 0,128043 & 0,110573 \\
0,32521 & 0,116497 & 0,099059 & 0,100666 \\
0,1154 & 0,073611 & 0,09301 & 0,120185 \\
0,05133 & 0,147064 & 0,150511 & 0,145978 \\
0,09015 & 0,17852 & 0,11645 & 0,123538 \\
0,06912 & 0,119671 & 0,088445 & 0,125442 \\
0,17295 & 0,20071 & 0,137144 & 0,148334
\end{array}\right) \times\left(\begin{array}{l}
0,417978 \\
0,294382 \\
0,168539 \\
0,119101
\end{array}\right)=\left(\begin{array}{l}
0,119687 \\
0,083311 \\
0,198912 \\
0,099893 \\
0,107502 \\
0,124572 \\
0,093967 \\
0,172157
\end{array}\right)
$$

Dari perhitungan di atas diperoleh:

$$
\begin{array}{ll}
1=0,119687 & 5=0,107502 \\
2=0,083311 & 6=0,124572 \\
3=0,198912 & 7=0,093967 \\
4=0,099893 & 8=0,172157
\end{array}
$$

Dari hasil di atas diketahui bahwa urutan prioritas Bank XXX yang mempunyai kriteria kinerja yang paling baik adalah sebagai berikut: Divisi 3 : Divisi Teknologi Informasi

Divisi 8 : Divisi Logistik

Divisi 6 : Divisi Perbankan Internasional

Divisi 1 : Divisi Audit Internal

Divisi 5 : Divisi Perbankan Konsumer

Divisi 4 : Divisi Pengembangan Operasi

Divisi 7 : Divisi Sumber Daya Manusia

Divisi 2 : Divisi Keuangan dan Akuntansi

\section{KESIMPULAN}

Berdasarkan pembahasan sebelumnya, maka dapat ditarik kesimpulan sebagai berikut: pemberian kriteria-kriteria dalam penentuan kinerja dapat membantu dalam mengambil keputusan untuk menentukan kinerja divisi yang berprestasi, Dengan menetapkan metode Analytical Hierarchy Proccess (AHP) proses penilaian kinerja lebih efisien sehingga pihak Bank lebih cepat memutuskan divisi yang berprestasi dalam bekerja, Sistem pengambilan keputusan dengan menggunakan metode Analytical Hierarchy Procces (AHP) telah membantu pihak Bank dalam menentukan pemilihan kinerja divisi yang berprestasi.

\section{DAFTAR PUSTAKA}

[1] Badriah, Nurlailah, 2012, Perancangan Kinerja Customer Relationship Management dengan Menggunakan Metode Customer Relationship Management Scorecard, Jurnal Teknik Industri, Universitas Trisakti, Jakarta,

[2] Mokodongan, Asminar, 2010, Analisis Penerapan Program Customer Relationship Management Hubungannya dengan Loyalitas Pelanggan, Jurnal Studi Kasus di Swiss Belhotel Malecosan Manado Fakultas Sastra dan Budaya, Universitas Negeri Gorontalo, Manado,

[3] Buttle, Francis, 2009, Customer Relationship Management Concepts and Technologies, Hungary: Elsevier Ltd,

[4] Latifah, Siti, 2005, Prinsip-Prinsip Dasar Analytical Hierarchy Process”, Jurnal Studi Kasus Fakultas Pertanian, Universitas Sumatera Utara (USU), Medan,

[5] Bushan, Navneet, 2004, Strategic Decision Making, India: CREAX Information Technologies. 